\title{
Oral hygiene in primary schoolchildren in Benin City, Nigeria
}

\author{
WOLE ALAKIJA \\ From the Department of Community Health, University of Benin
}

SUMMARY Oral hygiene was assessed in children from two primary schools in Benin City, Nigeria. Good oral hygiene was not related to the socioeconomic class of the children but to the method of cleaning the teeth. Girls had better oral hygiene than boys. It is suggested that the local method of using chewing sticks should be encouraged, and emphasis placed on frequency and thoroughness of use.

Oral hygiene in Nigerian children has been reported as being very poor ${ }^{1}$ and this has been blamed on the traditional method of cleaning teeth with a chewing stick. In a previous study of oral hygiene in children in Benin City, ${ }^{2}$ the numbers studied (five boys and 10 girls) were too small for any significant conclusions to be made. In this study, therefore, a large group of children (796) were examined in order to obtain a more meaningful assessment.

\section{Material and methods}

The survey was carried out from October to December 1979 by two medical students of the University of Benin who had been attached for two weeks to the department of dentistry of the university.

Two primary schools were chosen for their particular characteristics. Adesuwa school (girls) is a free government school attended mainly by pupils of low socioeconomic status. Emotan school (mixed) is a private fee-paying school where most pupils have parents of high socioeconomic status.

There are six classes in each school with at least three sections in each class. Two sections were chosen at random and all the pupils present on the day of the examination were included in the study.

It was felt that if the medical students' results during the trial survey showed a high sensitivity and specificity when compared with the results of the consultant dental surgeon who had taught them to examine teeth for oral debric and calculus, their subsequent survey at the chosen schools would be of a reasonable validity. After two weeks of training at the department of dentistry, a trial survey was carried out at the University of Benin staff school using 100 randomly chosen children. The results obtained by the students were compared with those of the consultant dental surgeon.

Because examiners differ in their assessment of oral health and because of the need for close agreement, the students examined each child independently and when their judgements differed a joint reassessment was made. Not more than five pupils a day were examined by each student in a well-lit classroom in the three schools.

The method of examination has been described in a World Health Organisation handbook. ${ }^{3}$ Oral hygiene in this study has been regarded as the state of oral cleanliness. Evidence for calculus in contact with the gingival margin was determined by direct inspection and with a mouth mirror, and tested with a periodontal probe to confirm that it was in fact calcified. The probe was sterilised in Hibitane before every use. Green and Vermillion ${ }^{4}$ used oral debris and dental calculus scores as a method of classifying oral hygiene status. In this study the method used was similar to that of Henshaw, ${ }^{2}$ who classified oral hygiene as 'good', 'fair', 'poor', or 'bad', but poor and bad were combined into a single group in this study.

A questionnaire was completed for each pupil examined in the two schools. The information requested included age, sex, and method and frequency of cleaning teeth.

\section{Results}

In the trial survey of 100 randomly selected children, the conclusions of the students compared with those of their instructor gave the following results:

(a) Of the 50 children diagnosed as having 'good' 
oral hygiene by the students, 48 were confirmed as good by the consultant dental surgeon (sensitivity $=96 \%$ ).

(b) Of the $\mathbf{4 0}$ children diagnosed as having 'fair' oral hygiene by the students, 36 were found to be fair by the consultant (sensitivity $=90 \%$ ).

(c) Seven children were diagnosed as having 'poor' and 'bad' oral hygiene by the students, and three more were found to be in this category by the consultant (specificity $=\mathbf{7 0 \%}$ ).

In the subsequent survey 796 pupils were examined, 395 from Emotan and 401 from Adesuwa schools. Their age distribution is shown in Table 1. Girls had higher oral hygiene scores than boys, and there was little difference between the scores of girls in the two schools (Table 2).

Because oral hygiene is better among girls than boys, the girls in the two schools were compared, with the following results:

(1) Differences between those who used toothbrushes and those who used the local chewing sticks were not statistically significant $\left(\chi^{2}=2 \cdot 85\right.$; $1 \mathrm{df} ; \mathrm{p}<0.05)$. This points to the fact that provided the teeth are properly cleaned the method used may

Table 1 Age distribution of pupils

\begin{tabular}{|c|c|c|c|c|}
\hline \multirow{2}{*}{$\begin{array}{l}\text { Age } \\
\text { (years) }\end{array}$} & \multicolumn{2}{|c|}{ Emotan school } & \multicolumn{2}{|c|}{ Adesuwa school } \\
\hline & No. & $\%$ of total & No. & $\%$ of total \\
\hline 6 & 70 & $17 \cdot 7$ & 78 & 19.6 \\
\hline 7 & 65 & 16.5 & 72 & $17 \cdot 9$ \\
\hline 8 & 70 & $17 \cdot 7$ & 51 & $12 \cdot 7$ \\
\hline 9 & 65 & $16 \cdot 5$ & 58 & $14 \cdot 5$ \\
\hline 10 & 65 & $16 \cdot 5$ & 61 & $15 \cdot 2$ \\
\hline 11 & 60 & $15 \cdot 1$ & 49 & $12 \cdot 2$ \\
\hline 12 & - & - & 32 & $7 \cdot 9$ \\
\hline Total & 395 & 100 & 401 & 100 \\
\hline
\end{tabular}

not be important in the maintenance of good oral hygiene.

(2) Differences between those who used the chewing sticks only were not statistically significant $\left(\chi^{2}=0.88 ; 1 \mathrm{df} ; \mathrm{p}<0.3\right)$.

(3) There was a statistically significant difference between the girls in the two schools who used toothbrushes only $\left(\chi^{2}=9.53 ; 1 \mathrm{df} ; \mathrm{p}<0.01\right)$. The explanation of this was that $80 \%$ of girls in Emotan school brushed their teeth more than once a day whereas only $30 \%$ did so in Adesuwa school.

The relationship between the three main methods of cleaning (toothbrush, chewing stick, or both) and the oral health of the children in the two schools is shown in Table 3.

\section{Discussion}

Good oral hygiene can be achieved by using either toothbrushes or chewing sticks but whichever method is used the important point is the thoroughness of cleaning. Although a toothbrush may be more efficient than a chewing stick, ${ }^{2}$ and efficiency may increase with increasing age, toothbrushes and toothpaste are much more expensive. Small wonder, then, that more pupils of the elite, fee-paying school used toothbrushes. However, since the majority of primary school children in Bendel State come from poor families, the use of chewing sticks should be encouraged with emphasis on the need for regular and thorough cleaning.

I thank Dr. Nornoo, the consultant dental surgeon; the students, Mr. Inyang and Mr. Ijoko; and the headmistresses of the schools.

Table 2 Distribution of oral hygiene scores

\begin{tabular}{|c|c|c|c|c|c|c|c|}
\hline \multirow[b]{3}{*}{ Score } & & \multicolumn{4}{|c|}{ Emotan school } & \multirow{2}{*}{\multicolumn{2}{|c|}{$\frac{\text { Adesuwa school }}{\text { Girls }}$}} \\
\hline & & \multicolumn{2}{|l|}{ Boys } & \multicolumn{2}{|l|}{ Girls } & & \\
\hline & & No. & $\%$ of total & No. & $\%$ of total & No. & $\%$ of total \\
\hline \multirow[t]{2}{*}{ GOOD } & No calculus & & & & & & \\
\hline & $\begin{array}{l}\text { No soft deposit } \\
\text { or debris }\end{array}$ & 85 & $40 \cdot 1$ & 100 & 54.6 & 239 & 59.6 \\
\hline \multirow[t]{2}{*}{ FAIR } & No obvious calculus & & & & & & \\
\hline & $\begin{array}{l}\text { Moderate soft deposit } \\
\text { or debris }\end{array}$ & 105 & $49 \cdot 5$ & 71 & $38 \cdot 8$ & 156 & 38.9 \\
\hline \multirow[t]{3}{*}{ POOR } & Much calculus & & & & & & \\
\hline & $\begin{array}{l}\text { Much soft deposit } \\
\text { or debris }\end{array}$ & 22 & $10 \cdot 4$ & 12 & $6 \cdot 6$ & 6 & 1.50 \\
\hline & Total & 212 & 100 & 183 & 100 & 401 & 100 \\
\hline
\end{tabular}


Table 3 Method of cleaning teeth

\begin{tabular}{|c|c|c|c|c|c|c|c|c|c|c|}
\hline \multirow[b]{4}{*}{ Method } & \multicolumn{5}{|c|}{ Emotan school (girls) } & \multicolumn{5}{|c|}{ Adesuwa school } \\
\hline & \multicolumn{4}{|c|}{ Oral health } & \multirow[b]{3}{*}{ Total } & \multicolumn{4}{|c|}{ Oral health } & \multirow[b]{3}{*}{ Total } \\
\hline & \multicolumn{2}{|c|}{ Good } & \multicolumn{2}{|c|}{ Fair/Poor } & & \multicolumn{2}{|c|}{ Good } & \multicolumn{2}{|c|}{ Fair/Poor } & \\
\hline & No. & $\%$ of total & No. & $\%$ of total & & No. & $\%$ of total & No. & $\%$ of total & \\
\hline Always uses toothbrush & 76 & $57 \cdot 1$ & 57 & $42 \cdot 9$ & 133 & 61 & $76 \cdot 2$ & 19 & $23 \cdot 8$ & 80 \\
\hline Always chewing stick & 15 & $48 \cdot 4$ & 16 & $51 \cdot 6$ & 31 & 160 & $57 \cdot 1$ & 120 & $42 \cdot 9$ & 280 \\
\hline Chewing stick and toothbrush & 9 & $47 \cdot 3$ & 10 & $52 \cdot 7$ & 19 & 18 & $45 \cdot 0$ & 23 & $55 \cdot 0$ & 41 \\
\hline Total & 100 & $54 \cdot 6$ & 83 & $45 \cdot 4$ & 183 & 239 & 59.6 & 162 & $40 \cdot 4$ & 401 \\
\hline
\end{tabular}

Reprints from Dr. Wole Alakija, Department of Community Health, School of Medicine, College of Medical Sciences, University of Benin, Benin City, Nigeria.

\section{References}

${ }^{1}$ Sheiham A. The prevalence of dental caries in Nigerian populations. (PhD thesis University of London). $\mathrm{Br}$ Dent J 1977; 123: 144.
${ }^{2}$ Henshaw NE. A survey of dental caries and oral hygiene in the southern zone of Nigeria. Niger Med J 1974; 4 (3): 185.

${ }^{3}$ World Health Organisation. Basic Health Surveys, 2nd edn. Geneva: WHO, 1977.

${ }^{4}$ Green JC, Vermillion JR. Oral hygiene under a method for classifying oral status. J Am Dent Assoc 1960; 61: 172. 